\title{
DEVELOPMENT AND INTEGRATION OF TECHNICAL WRITING SKILLS ORIENTED TOWARD ENGINEERS’ NEEDS
}

\author{
Anouk Desjardins, Evelyne Doré and Raymond Desjardins \\ Department of Civil, Geological and Mining Engineering, Polytechnique Montréal \\ Anouk.desjardins@polymtl.ca, evelyne.dore@polymtl.ca, raymond.desjardins@polymtl.ca
}

\begin{abstract}
Written communication is among the skills future engineers must develop and master in order to excel in their profession. Employers and the Canadian Engineering Accreditation Board also require this skill. Students in all Polytechnique Montréal programs have one course credit in their program devoted to written and oral communication. The training is provided by Polytechnique's Centre d'études complémentaires (centre for complementary studies) for all programs.

Despite the implementation of this process, we noted that civil engineering students had difficulty employing good technical writing practices in their work, such as capstone projects, lab reports and hands-on assignments. The students saw written communication workshops as satellite training and employed their learning only to a small degree in their other courses. The students were essentially stagnating instead of making progress throughout the bachelor's degree.

In response to these issues, a common approach was put into place for the entire civil engineering program as a complement to the trainings provided by the Centre d'études complémentaires. This approach has been a success; student response has been positive and improvement has been observed in the courses where writing is required. The students especially appreciate this when they perform their mandatory internship, because they feel this training makes a difference and helps them distinguish themselves.
\end{abstract}

Keywords: technical writing, communication skills, crosscurricular competencies, learning progress

\section{INTRODUCTION}

Written communication is part of the skills that future engineers must develop and master in order to excel in their profession. Internship supervisors, employers and the Canadian Engineering Accreditation Board also require this skill.

Several professors in Polytechnique Montréal's civil engineering program noted major lacunae in technical writing. Some students were not mastering the elementary basics of written communication; others mastered the basics, but did not know how to apply them in the context of specialized technical writing. They had difficulty choosing content, bringing forth ideas, effectively using figures and tables, structuring text and adopting the appropriate tone for this type of writing.

All Polytechnique students must pass one course credit devoted to written and oral communication. This course credit is managed by the Équipe de communication écrite et orale (the written and oral communications team, or CÉO) at Polytechnique's Centre d'études complémentaires, and the subject is taught in the form of workshops given by written and oral communication specialists. The approach for acquiring this course credit is innovative and is part of a program-wide approach [1]. However, we noted that civil engineering students had difficulty employing their learned skills in their work, such as capstone projects, lab reports and hands-on assignments. The students saw written communication workshops as satellite training and employed their learning only to a small degree in their other courses. Even students with strong written communication skills had difficulty with the requirements of technical writing. Students tended to adapt to a professor in order to get a good grade, rather than employing technical writing best practices. As such, the students were stagnating instead of making progress throughout the bachelor's program.

In response to these issues, a common approach was put into place for the entire civil engineering program as a complement to the training workshops provided by the Centre d'études complémentaires.

This article first presents the context and evolution of written communication teaching at Polytechnique Montréal. Next, it presents the methodology employed to propose solutions, and lastly, it examines the implementation of solutions in the civil engineering program, and their results.

\section{CONTEXT}

Technical writing was first taught at Polytechnique Montréal in 1984 as part of a methodology course. At that time, employers had already identified a need to improve students' written communication skills [2]. In 2004, 
Polytechnique Montréal undertook a complete revamping of all its engineering programs [3]. The bachelor's in engineering is a four-year program comprising 120 credits, of which 108 were mandatory. The changes included the addition of a capstone project for each year of the bachelor's program, the addition to all programs of two course credits on interpersonal relationships and teamwork, and, lastly, one course credit dedicated to written and oral communication.

\subsection{Approach for all programs}

When the programs were revamped, the methodology course was abolished and an innovative approach to written and oral communication was implemented for all programs. This cross-program approach is centred on addressing the personalized needs of each student in the area of written and oral communication [2].

During their first semester, all students must take a written and oral communication placement test. All the placement tests are managed and corrected by the written and oral communications team (CÉO) at the Centre d'études complémentaire. Once the placement tests are graded, the students receive a prescription for personalized training in the form of workshops, based on their written communication training needs. The workshop topics are as follows: outlines and organization, citations and references, grammar, tables and figures, vocabulary and style, resume writing, and writing tools. These workshops are given by written and oral communication specialists at Polytechnique's Centre d'études complémentaires and must be completed during the second semester.

Each workshop is 90 minutes long and the students must complete a homework assignment for the workshop in the following ten business days to pass the workshop. Since 2009, the mandatory internship report constitutes the final test in this process; it is produced between the 55- and 80credit mark during the third year of the bachelor's program. The content of the internship report is assessed by the internships department, and the writing quality is assessed by the written and oral communications team at the Centre d'études complémentaires. This adjustment has allowed students to work on a concrete report intended for a client and to improve the quality of the internship reports they submit to employers. Despite these adjustments, all professors continued to note lacunae in technical writing. Employers, who wanted graduates to have better mastered this skill, echoed this observation.

To obtain the course credit for written and oral communication set out in the academic program, students must take all the workshops prescribed to them, pass all the homework assignments and obtain a satisfactory evaluation for their internship report.

\subsection{Strengths and limits of the approach}

Students experience two types of technical writing challenges. The first concerns basic lacunae in written
French as a result of previous studies: grammar and text structure, for instance. The breadth of the lacunae varies depending on the student, as examples: female students generally have fewer difficulties in grammar than students and major difficulties are often noted among students whose mother tongue is not French. In this context, the individual training prescription provided by the crossprogram approach is quite appropriate.

The second type of difficulty concerns technical writing specific to engineering. Students have trouble writing an engineering technical document for a client. They have multiple difficulties: autonomously choosing the content of a report, writing style, technical document structure, effective use of tables and figures, and collaborative writing. These difficulties also affect students who have no identified lacunae in their written French. Students have difficulty writing memos for clients and regularly tended to write the report for the professor in order to get a good grade.

As well, students saw the workshops as being satellite training, and they employed what they had learned to only a minimal degree in courses that require writing.

In response to these issues, a common approach was developed and implemented for the entire civil engineering program.

\section{METHODOLOGY}

To encourage buy-in to the project, the work needed to be done with a cross-curricular approach and involve all the people who were likely to make this new approach a success, meaning all professors in the civil engineering program, the person in charge of written and oral communication workshops at the Centre d'études complémentaire, the head of the civil engineering program, and the civil engineering program director [4].

\subsection{Consulting with professors}

To begin, the professors in the civil engineering program were contacted and asked to respond to a questionnaire (Appendix 1). This questionnaire addressed their written communication requirements for engineers, the lacunae and strengths they had observed in their students, and their specific needs. All the professors teaching project-based courses took part in the project, answered the questionnaire and attended meetings to validate the questionnaire responses. A number of other professors also answered the questionnaire and were met with, mainly professors teaching courses that require writing (ex.: technical reports and lab reports). Overall, $70 \%$ of professors in the civil engineering program responded positively to the call-out. The analysis of questionnaire responses and the summary of meeting notes clearly showed a common vision among all professors in regard to technical writing. Some elements were formulated differently, but meant the same thing. The 
majority of professors expressed enthusiasm about the project and agreed to implement elements in their courses to help develop technical writing throughout the entire bachelor's program. A number of them also proposed ideas of interest to enhance the project.

\subsection{Work with the CÉO team}

To propose a common written communication approach for the entire civil engineering program that would best meet the need for specialized technical writing for engineers and, above all, to engage students in a constant improvement process throughout the whole bachelor's program, the following goals were set:

1. Raise students' awareness of the importance of technical writing in an engineering career, with concrete examples taken from engineering practice and contact with engineers;

2. Present the concepts of specialized technical writing [5] in lecture form and encourage active learning through hands-on assignments where immediate feedback is provided;

3. Help students develop a solid work method by teaching individual and collaborative writing strategies [6];

4. Evaluate the development of written communication skills in a cross-curricular manner throughout the whole bachelor's program, among others through projectbased courses;

5. Maintain the strengths of the existing approach, meaning individual prescriptions for workshops on writing basics and the link with the internship report.

\subsection{Industry consultation}

The objectives and the process as a whole were presented to the Conseil consultatif en génie civil de Polytechnique Montréal (Polytechnique Montréal’s civil engineering advisory council, known as the Cocep de génie civil). Civil engineers sit on the advisory council; their objective is to ensure that the programs offered at Polytechnique Montréal meet the industry’s needs. The Cocep de génie civil responded favourably to the changes proposed for technical writing in the civil engineering program.

\section{IMPLEMENTATION OF MANDATORY WORKSHOPS IN THE CIVIL ENGINEERING PROGRAM}

The basic structure of the cross-program approach was maintained: placement test, prescription of workshops to meet the needs observed for each student, final test by means of the internship report. However, new mandatory workshops for all civil engineering students have now been added to the existing workshops. These workshops were defined in collaboration with the CÉO team to ensure the approaches would be complementary. These workshops are given by civil engineers to strengthen the link between technical writing and professional practice and the link with other courses in the program.

\subsection{Mandatory workshops in civil engineering}

Table 1 lists the workshops offered by the CÉO in response to the placement tests (individualized prescription) and the mandatory workshops for civil engineering students. Note that one of the workshops provided by the CÉO is mandatory for all students.

Table 1: Written communication workshops

\begin{tabular}{|l|l|l|}
\hline Workshops & Prescription & Provided by \\
\hline Writing method & Mandatory & Civil engineer \\
\hline Report structure & Mandatory & Civil engineer \\
\hline $\begin{array}{l}\text { Tables and } \\
\text { figures }\end{array}$ & Mandatory & Civil engineer \\
\hline Writing tools & Mandatory & Civil engineering \\
\hline $\begin{array}{l}\text { Citations and } \\
\text { references }\end{array}$ & $\begin{array}{l}\text { Based on } \\
\text { placement } \\
\text { test }\end{array}$ & CÉO \\
\hline Grammar & $\begin{array}{l}\text { Based on } \\
\text { placement } \\
\text { test }\end{array}$ & CÉO \\
\hline Resume writing & Mandatory & CÉO \\
\hline
\end{tabular}

Teaching materials were designed for mandatory workshops for civil engineering students, taught by civil engineers. The content of the new material was created in such a way as to develop specific skills in writing technical reports, on the basis of lacunas observed in the courses, meetings with professors, and the technical writing requirements for civil engineers. A writing guide for engineers [7] was also written. It is used as a reference document in the workshops, but also as a technical writing reference in the other courses of the civil engineering program.

Mandatory workshops, taught by engineers, were given in the civil engineering program for three years, from 2013 to 2016 .

\subsection{Results}

The writing guide was a success. Students use it in a number of courses, and some use it during their internships.

The workshop formula is perfectly suited to a personalized training prescription context based on the difficulties of each student. The workshops aim to make up for specifics lacunas.

However, the workshop formula is not optimal for helping students progress from one assignment to the next, which poses a problem when it comes to the mandatory workshops in civil engineering. Because the students change from one workshop to the next, they are not all prescribed the same workshops, they are also free to take the workshops in the order of their choosing, so it is impossible to build on the learning from a previous session 
and difficult to make progress in learning from one session to the next. It is also not possible to assign homework that touches on multiple aspects of technical writing, which quickly becomes a limiting factor.

\section{INCLUSION IN CIVIL ENGINEERING COURSES}

Starting in the Fall 2017 semester, the material taught in the four mandatory workshops for civil engineering students has been included in the mandatory courses CIV1000 - Gestion des études, santé et sécurité (on managing studies, health and safety) and CIV1910 - Projet d'analyse expérimentale d'ouvrages civils (first capstone project of the civil engineering program). Managing this material within the civil engineering program gives more latitude to plan a learning progression and to align it with the program's other courses.

In the CIV1000 course, students must complete an assignment that includes all the technical writing concepts they have learned. They are supported by the professor during the writing process and receive targeted feedback. In the CIV1910 course, students apply technical writing concepts within a capstone project and receive feedback throughout the process. The four capstone projects in the civil engineering program use the writing guide and ensure that the students progress.

Because the writing training is provided in courses within the civil engineering program, the students are less likely to see technical writing training as a satellite training. They continue to have the CÉO's support based on the results they obtain in the placement test and are guided to improve their technical writing skills throughout their bachelor's program.

\subsection{Difficulty}

Developing students' technical writing skills throughout the bachelor's program requires time, energy, and professors' collaboration. The professors collaborated to establish a common vision of technical writing for the civil engineering program. However, it is much more difficult to obtain long-term commitment and require rigour from everyone in applying technical writing principles and providing targeted feedback to help students progress.

\subsection{Success}

It is impossible to make all professors adhere to the process. That being said, to create a ripple effect, only some professors must buy in. The students develop their skills by applying technical writing principles in all their work. They receive targeted feedback from the professors who are committed to the process. They don't receive targeted feedback from the professors who are not committed to the process, but they get good grades because they did good work, which encourages them to pursue their efforts and thus make progress in their technical writing.

Teachers outside the civil engineering program have noticed students' technical writing progress. The course in applied ethics for engineering is provided by Polytechnique's Centre d'études complémentaires for students in all programs. The course director can easily tell which students in the course are from civil engineering thanks to the quality of their work: their writing is well organized, effective and of high quality.

Civil engineering and geological engineering professors are increasingly asking their graduate students to apply the principles set out in the writing guide for engineers. Professors from other programs, including chemical engineering and geological engineering, want to use the teaching material and the writing guide for engineers in their courses.

Engineering students do not particularly like writing courses. However, some civil engineering students recognize that the training and support provided throughout their bachelor's program is beneficial. Civil engineering students say it is difficult to work in collaboration with students from other programs who have not received the same support. Civil engineering students also note that they distinguish themselves in their internships and when they enter a job because of their technical writing skills, which represents a significant success factor.

\section{CONCLUSION}

The all-program approach for Polytechnique put into place by the CÉO makes it possible to diagnose students' difficulties and to offer them personalized training in the form of workshops to help them improve on their lacunas. This approach has been a success, but does not render it possible for all students to make progress in specialized technical writing, and does not allow students to apply concepts in a concrete way in their courses, apart from the internship report.

The technical writing teaching materials developed, and technical writing courses given by engineers in two courses in the civil engineering program allow students to invest the learned concepts in all courses requiring writing. Because these specialized technical writing concepts are aligned with the other courses in the civil engineering program, students can develop and maintain their technical writing skills throughout the bachelor's program. The students no longer adapt to a given professor's requirements, but follow best practices in technical writing to which their civil engineering professors adhere and which correspond to the industry's requirements. 


\section{Acknowledgements}

The authors would like to thank Dominique Chassé, head of the CÉO at Polytechnique Montréal until 2015, for her openness and her valuable collaboration, as well as Sylvie Hertrich and Esther Savoie, respectively head of the CÉO since 2015 and CÉO coordinator, for having agreed to pursue the collaboration that began with Dominique. Lastly, thanks to André Lomone, who provided considerable help in developing the teaching material and writing the writing guide for Word tools.

\section{References}

[1] Richard Prégent, Huguette Bernard and Anastassis Kozanitis, Enseigner à l'université dans une approche-programme. Montreal: Presses Internationales Polytechnique, 2009, 330 pp.

[2] Sylvie Hertrich and Dominique Chassé "Developing Communication Skills during Undergraduate Studies: A Personalized Approach," in Proc. CEEA14 paper 53 Canadian Engineering Education Association (Canmore, AB, Canada, June 8-11, 2014), 2014, 4 pp.

[3] Pierre Lafleur, Yves Boudreault and Richard Pregent, "Meeting the challenge of reviewing eleven engineering programs," in Proc. ASEE paper AC-2008-696 American Society of Engineering Education (Pittsburg, PA, June 22-25, 2008), 2008, 13 pp.

[4] Anouk Desjardins, Evelyne Doré, Raymond Desjardins and Dominique Chassé, "Technical Writing Course Designed for the Reality of an Engineer," in Proc. ICEE paper 54 International Conference on Engineering Education, (Turku, Finland, July 30-August 3, 2012), 2012, 6 pp.

[5] H. Silyn-Roberts, Professional Communications: A Handbook for Civil Engineers. Reston: American Society of Civil Engineers, 2005, 268pp.

[6] A. V. Mamishev and S. D. Williams, Technical Writing for Teams using STREAM Tools. Hoboken: John Wiley \& Sons, 2010, 264pp.

[7] Anouk Desjardins, Evelyne Doré and André Lomone, Guide de rédaction pour ingénieurs, Presses Internationnales Polytechnique 3rd ed., 2018, 168 pp.

\section{APPENDIX 1: SURVEY}

\section{Report structure}

1. Does the following general report structure is adequate for the needs of your course?

a. Cover page (with name and number of the course, title, student's name and identification, teacher's name, due date)

b. Summary (1 to 2 pages)

c. Table of content; list of figures; list of table

d. Introduction
i. Context
ii. General objectives
iii. Mandate

e. Main body

f. Conclusion and recommendations

g. References

h. Appendix

2. Which elements wish you to find in the body text (e.g. material and methods, design method, discussion, etc,)?

\section{References}

1. Do you allow importance to references in a technical report?

2. Would you like references cited in-text in addition to the reference list at the end of the report?

3. Which reference style do you prefer?

a. APA: Citation in the text (name of authors, date), listed in alphabetical order in the references list.

b. IEEE: Citations in the text: numbered between [], listed in numerical order in the reference list.

\section{Progress report}

1. When students must submit progress reports and a final report, do you wish that:

a. The global context presented in all reports;

b. The general(s) objective(s) of the project and the specific(s) objective(s) of the report both presented in the reports;

c. The specific(s) objective(s) of the report is enough, no need to present the general objective.

\section{Plans / design drawings, tables and figures}

1. Do you prefer that plans / design drawings be presented:

a. Throughout the text in the main body of the report;

b. Presented in a plans booklet at the beginning of the appendices (only design plans are concerned by this question, not figures and graphs).

2. Does this way to present tables and figures is adequate for you course: number and title of a figure placed below the figure and number and title of a table placed above the table.

3. Are you according importance to the following elements:

c. Design of the tables and integration in the text; 
d. Tables and figures announced at the beginning of the explanation;

e. Use as much as possible sketches, figures, graphs to illustrate the matter.

\section{Writing style}

1. When students write a report in your course, who is the target reader?

a. The client;

b. The teacher;

c. Both.

2. Do you allow importance to neutral tone? Example : do not use us, our bridge, our team, our project, etc.

\section{Open questions}

1. What are the most common mistakes done by students in technical reports written in your courses? Could you provide some examples?

2. What are the weakest points in the technical reports written by your students?

3. What are the strongest points in the technical reports written by your students?

4. Do you have any other specific requirements for the reports written in your courses? Could you specify those requirements?

5. Do you already have a document presenting all the requirements for the writing reports in your course? Could we have a copy? 